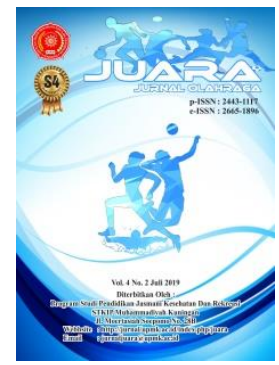

Tingkat Kondisi Fisik Atlet Bolabasket PPLOP Jawa Tengah Ditentukan dengan Tes dan Pengukuran Khusus

\title{
Determining Physical Fitness for PPLOP Basketball Athletes in Central Java using Sport-specific Test and Measurement
}

\author{
Agam Akhmad Syaukani $^{1}$, Nur Subekti ${ }^{2}$, Eko Sudarmanto ${ }^{3}$ \\ 1,2,3 Faculty of Teacher Training and Education, Universitas Muhammadiyah Surakarta, Jl. A. Yani, \\ Mendungan, Pabelan, Kec. Kartasura, Kabupaten Sukoharjo, Jawa Tengah 57162, Indonesia \\ Email: aas622@ums.ac.id ${ }^{1}$, ns584@ums.ac.id ${ }^{2}$, es348@ums.ac.id $^{3}$
}

\begin{tabular}{l} 
Info Artikel \\
\hline Sejarah Artikel: \\
Diterima 06 November 2019 \\
Disetujui 01 Januari 2020 \\
Dipublikasikan 08 Januari \\
2019
\end{tabular}

Keywords:

Physical conditions,

tests and

measurements,

basketball

\begin{abstract}
Abstrak
Tingkat kondisi fisik dapat secara langsung mempengaruhi keberhasilan tim dalam memenangkan pertandingan. Penelitian ini bertujuan untuk mengetahui tingkat kondisi fisik atlet bola basket PPLOP Jawa Tengah. Sebanyak 13 atlet dilibatkan dalam penelitian ini. Metode penelitian yang digunakan yakni deskriptif kuantitatif menggunakan teknik tes dan pengukuran yang khusus disesuaikan dengan kebutuhan cabang olahraga bola basket yang meliputi tes lari 60-m, sprint fatigue test, push-up maksimal, sit-up 1 menit, beep test, dan V-sit. Secara berurutan dimaksudkan untuk mengukur kecepatan, daya tahan anaerobik, daya tahan muskuler ekstrimitas atas, daya tahan muskuler perut, daya tahan aerobik, dan kelentukan. Selain itu dilakukan uji beda menggunakan teknik ANOVA untuk mengetahui perbedaan kondisi fisik antara pemain inti dan pemain cadangan. Hasil yang diperoleh secara umum tingkat kondisi fisik pemain PPLOP dalam kondisi baik. Adapun daya tahan muskuler lengan dan bahu memerlukan peningkatan karena hasilnya yang dikategorikan kurang. Adapun perbedaan kapasitas fisik yang signifikan antara pemain inti dan pemain cadangan tercatat hanya pada jumlah push up $(p<0.05)$ yang dicatatkan. Penelitian ini dapat dimanfaatkan sebagai rujukan bagi pelatih dalam membuat program latihan serta mengadopsi jenis tes dan pengukuran yang dipilih dalam studi ini sebagai pedoman pengukuran fisik bagi atlet bola basket.
\end{abstract}

\footnotetext{
Abstract

The level of physical condition can directly affect the team's success in winning the match. The purpose of this study is to implement sportspecific test and measurement related to basketball to investigate the level of fitness for basketball athletes in Central Java highschool basketball team (PPLOP). The total of 13 athletes were signed for this study. Methods used to collect data were test and measurement containing of the following 60-m sprint test, sprint fatigue test, maximum push up, one minute push up, beep test and $V$-sit. These are sequentially intended to
} 
measure speed, anaerobic endurance, upper extremity muscular endurance, abdominal muscular endurance, aerobic endurance, and flexibility. In addition, a different test was conducted using ANOVA technique to determine differences in physical conditions between starters and reserve players. The results suggested that generally the level of physical condition of PPLOP players is in good condition. However, the muscular endurance of the arms and shoulders requires an increase because the results are categorized as less. The significant difference in physical capacity between starters and reserve players was recorded only in the number of push ups $(p<0.05)$ recorded. This research can be used as a reference for trainers in creating training programs and adopting the types of tests and measurements selected in this study as guidelines for physical measurement for basketball athletes.

C 2020 Agam Akhmad Syaukani, Nur Subekti, Eko Sudarmanto Under the license CC BY-SA 4.0

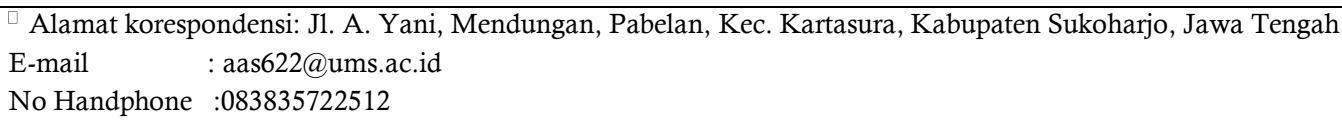

\section{PENDAHULUAN}

Permainan bola basket yang dikenal pada masa sekarang menuntut kondisi fisik yang prima dari atletnya. Bola basket masuk dalam kategori permainan kategori intermittent yang artinya melibatkan aktivitas fisik dengan intensitas tinggi, diselingi aktivitas fisik intensitas rendah dan periode istirahat(Abian-Vicen et al., 2014; Arazi, Coetzee, \& Asadi, 2012). Permainan yang berlangsung dalam intensitas tinggi memerlukan ketahanan fisik yang dapat berlangsung selama jalannya pertandingan. Permainan bola basket yang kompetitif juga turut melibatkan kontak fisik antar pemain. Jika kondisi fisik pemain tidak mampu menjawab tantangan permainan yang ada sekarang, maka dipastikan pemain atau tim yang bersangkutan akan gagal bersaing dan sulit mendapatkan prestasi pada cabang olahraga ini. Studi pada pemain elit mengungkapkan bahwa kesuksesan dalam bermain bola basket secara fisik lebih ditentukan oleh kapasitas anaerobik (Klausemann, Pyne, Foster, \& Drinkwater, 2012). Namun kapasitas aerobik juga tetap menjadi kebutuhan seorang pemain bola
basket(McInnes, Carlson, Jones, \& McKenna, 1995).

Secara umum, McKeag (2008) mengungkapkan setidaknya ada beberapa komponen kebugaran fisik yang harus dimiliki oleh setiap pemain bola basket, antara lain: (1) kapasitas aerobik, (2) kapasitas anaerobik, (3) kekuatan, (4) kecepatan, (5) kelincahan, (6) kelentukan, dan (7) profil massa tubuh. Tanpa adanya pembinaan fisik yang berkaitan dengan komponen-komponen diatas maka pembinaan prestasi atlet bola basket tidak akan dapat berjalan dengan optimal. Hal ini mengingat bahwa fisik merupakan dasar pengembangan keterampilan olahraga. Kondisi fisik akan berpengaruh pada penampilan atlet di lapangan permainan(Kuroda et al., 2015).

Studi terkait tingkat kondisi fisik atlet telah banyak dilakukan (Nasution, 2014; Nosa \& Faruk, 2013; Permadi, 2017; Priambodo, 2013). Namun studi tersebut tidak menyertakan atribut fisik yang secara lengkap berkaitan dengan cabang olahraga yang ditekuni. Misalnya studi sejenis dari Priambodo (2013) tidak menyertakan aspek daya tahan anaerobik, padahal aspek ini merupakan aspek fisik yang dominan ditemui dalam permainan bola basket (Abian-Vicen et 
al., 2014). Hal ini tentu menjadi catatan tersendiri mengingat bola basket memiliki kekhususan yang tidak dimiliki oleh olahraga lain(Puente, Abian-Vicen, Areces, Lopez, \& Del Coso, 2017). Keunggulan dari penelitian ini adalah menyertakan atrinut-atribut fisik yang langsung terkait dengan olahraga bola basket untuk diukur dan dievaluasi menggunakan seperangkat metode tes dan pengukuran yang khusus. Dalam penelitian ini atribut fisik yang disertakan meliputi daya tahan anaerobik, kecepatan, kekuatan, kelincahan, daya tahan aerobik, kelentukan, dan indeks massa tubuh. Tes dan pengukuran fisik hendaknya berangkat dari tujuan dan dirancang sedemikian rupa sesuai kebutuhan pemain bola basket sehingga tes dan pengukuran olahraga dapat dimanfaatkan sebagai sarana prediksi prestasi atlet serta program perekrutan atlet binaan (talent scouting) (Zhannisa \& Sugiyanto, 2015). Morrow (2015) menyebutkan bahwa setidaknya ada 4 hal yang harus dipenuhi untuk menciptakan tes dan pengukuran yang berkualitas diantaranya objektivitas, reliabilitas, relevansi, dan validitas. Relevansi artinya item tes dan pengukuran yang diberikan harus disesuaikan dengan kebutuhan fisik cabang olahraga yang bersangkutan. Tujuan dari penelitian ini adalah mengetahui tingkat kondisi fisik atlet bola basket PPLOP Jawa Tengah tahun 2019 menggunakan metode tes dan pengukuran yang relevan dengan cabang olahraga bola basket. Subjek penelitian ini adalah seluruh atlet PPLOP Bola Basket Jawa Tengah. Sedangkan objek pada penelitian ini adalah komponen fisik yang berkaitan dengan cabang olahraga bola basket yang meliputi kapasitas aerobik, kapasitas anaerobik, kekuatan, kecepatan, kelincahan, kelentukan, dan profil massa tubuh. Penelitian ini dapat melengkapi kajian tentang tes dan pengukuran, khususnya yang menyangkut cabang olahraga bola basket serta dapat dijadikan acuan bagi pelatih ataupun pemangku kepentingan bola basket dalam menyaring, menyeleksi dan mengevaluasi kondisi fisik atlet bola basket.

\section{METODE}

Sebanyak 13 atlet bola basket PPLOP Jawa tengah direkrut dalam penelitian ini sebagai subjek penelitian. Penelitian ini merupakan penelitian deskriptif-kuantitatif. Penentuan sampel penelitian ditempuh dengan menggunakan metode total sampling. Penelitian ini menggunakan teknik tes dan pengukuran cross sectional, yang artinya pengumpulan data dilakukan secara sekaligus pada suatu rentang waktu.

Variabel yang diukur antara lain: a) daya tahan anaerobik, b) kecepatan, c) kekuatan, d) kelincahan, e) daya tahan aerobik, f) kelentukan, g) indeks massa tubuh. Instrumen pengumpulan data yang digunakan untuk mengukur variabel diatas berturut-turut adalah sebagai berikut: a) sprint-fatigue test (Zagatto, Beck, \& Gobatto, 2009), b) sprint 60 m (Gurses \& Kamis, 2018), c) push-up dan situp test (American College of Sports Medicine, 2010), d) T-test (Semenick, 1990), e) Yo-yo test (Bangsbo, Graham, Johansen, \& Saltin, 1994), f) $V$-sit and reach(Amiri-Khorasani \& Kellis, 2015)

Jenis tes dan pengukuran dalam penelitian ini dipilih berdasarkan kesesuaiannya dengan cabang olahraga bola basket (McKeag, 2008). Seluruh subjek pemain dalam penelitian ini dalam kondisi sehat dan memahami setiap item tes yang diujikan. Subjek diberikan waktu untuk melakukan pemanasan sebelum dilakukan tes dan pengukuran. Hasil penelitian diolah menggunakan teknik statistik analisis deskriptif presentase untuk memberikan sebaran capaian subyek terhadap seluruh item tes dan pengukuran yang dilakukan. 
Uji beda dengan menggunakan one-way ANOVA juga dilakukan untuk mengetahui signifikansi perbedaan capaian kondisi fisik antara pemain inti dan pemain cadangan pada tim bola basket PPLOP Jawa tengah.

Gambar 1 Kerangka sistematis penelitian

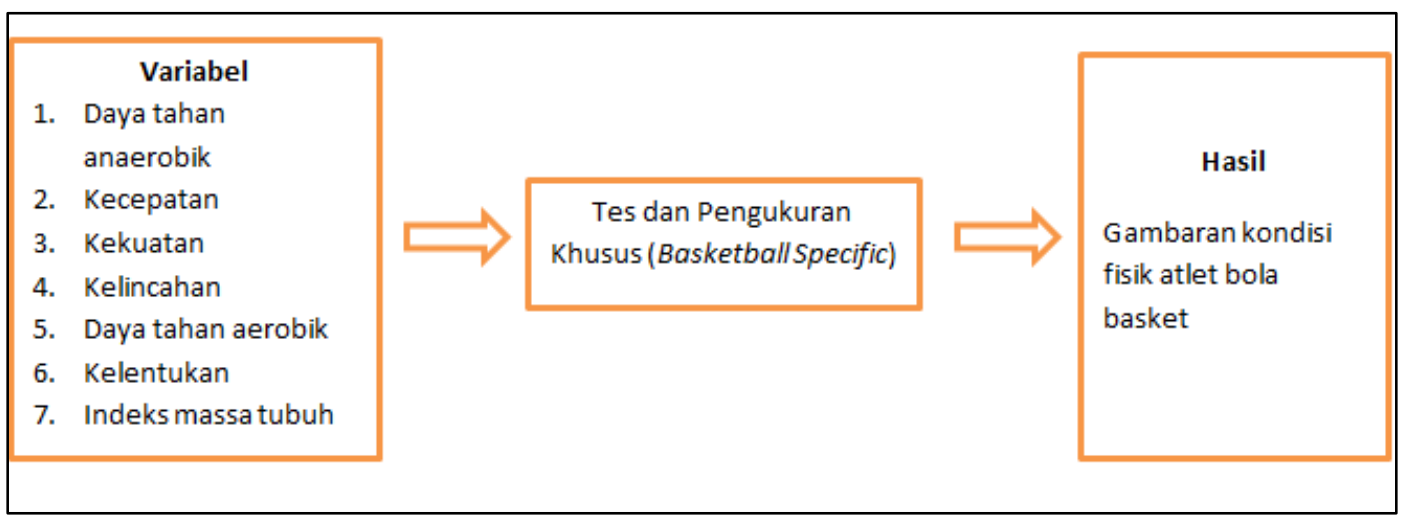

\section{HASIL DAN PEMBAHASAN}

\section{Hasil}

Hasil dari pengumpulan data merangkum nilai kondisi fisik untuk atlet bola basket PPLOP Jawa Tengah secara keseluruhan. Terdapat setidaknya 7 item tes dan 1 item pengukuran yang dilaksanakan. Informasi jenis tes dan hasilnya dapat dilihat pada Tabel 1. Penelitian ini juga menampilkan perbedaan tingkat kondisi fisik antara pemain inti dan pemain cadangan. Hasil uji beda dapat dilihat pada Gambar 2 .

Tabel 1 Nilai Tes Fisik Atlet PPLOP Jawa tengah Tahun 2019

\begin{tabular}{cllll}
\hline No. & \multicolumn{1}{c}{ Nama Tes } & \multicolumn{1}{c}{$\begin{array}{c}\text { Kondisi fisik yang } \\
\text { diukur }\end{array}$} & $\begin{array}{c}\text { Hasil } \\
(\text { Mean } \pm \text { SD) }\end{array}$ & Keterangan* \\
\hline 1. & Sprint fatigue test $(\%)$ & Daya tahan anaerobik & $\begin{array}{l}92.54 \pm 5.6 \\
\text { Kecepatan }\end{array}$ & $\begin{array}{l}6.84 \pm .96 \\
\text { Baik sekali }\end{array}$ \\
2. & Sprint 60 m (s) & Baik sekali \\
3. & Push up maksimal & Daya tahan kekuatan & $36.69 \pm 11.09$ & Kurang \\
4. & Sit up 1 menit (kali) & Daya tahan kekuatan & $49.08 \pm 5.89$ & Baik sekali \\
5. & T-test (s) & Kelincahan & $10.89 \pm .67$ & Sedang \\
6. & Beep test $(\mathrm{ml} / \mathrm{kg} / \mathrm{min})$ & Daya tahan aerobik & $47.17 \pm 3.8$ & Sedang \\
7. & V-sit and reach $(\mathrm{cm})$ & Kelentukan & $31 \pm 6.86$ & Sedang \\
8. & IMT $(\mathrm{kg} / \mathrm{m})^{2}$ & Profil massa tubuh & $21.55 \pm 1.57$ & Normal \\
\hline
\end{tabular}

*Norma tes dan pengukuran olahraga (American College of Sports Medicine, 2018)

Temuan di lapangan menunjukkan tingkat kondisi fisik atlet bola basket PPLOP Jawa Tengah dapat dikategorikan cukup baik. Hal ini dapat dilihat melalui sajian data dalam Tabel 1. Beberapa parameter seperti daya tahan anaerobik dan kecepatan berturut-turut memperoleh capaian yang baik sekali dengan nilai rata-rata $92.54 \%$ dan 6.84 s. Selain itu daya tahan kekuatan otot perut yang diukur dengan tes sit-up 1 menit menunjukkan hasil yang dikategorikan baik sekali dengan capaian rata-rata 49.08. Tiga parameter fisik memperoleh hasil yang dikategorikan sedang yakni kelincahan (10.89 s), daya tahan aerobik (47.17 $\mathrm{ml} / \mathrm{kg} / \mathrm{min})$, dan kelentukan $(31 \mathrm{~cm})$. Profil massa tubuh semua atlet dalam batas 
normal dengan nilai rata-rata IMT 21.55 $(\mathrm{kg} / \mathrm{m}) 2$.

Uji beda juga dilakukan untuk mengetahui perbedaan kondisi fisik antara pemain inti dan pemain cadangan pada tim bola basket PPLOP Jawa Tengah. Sebaran kondisi fisik disajikan secara komparatif melalui grafik pada gambar 2 .

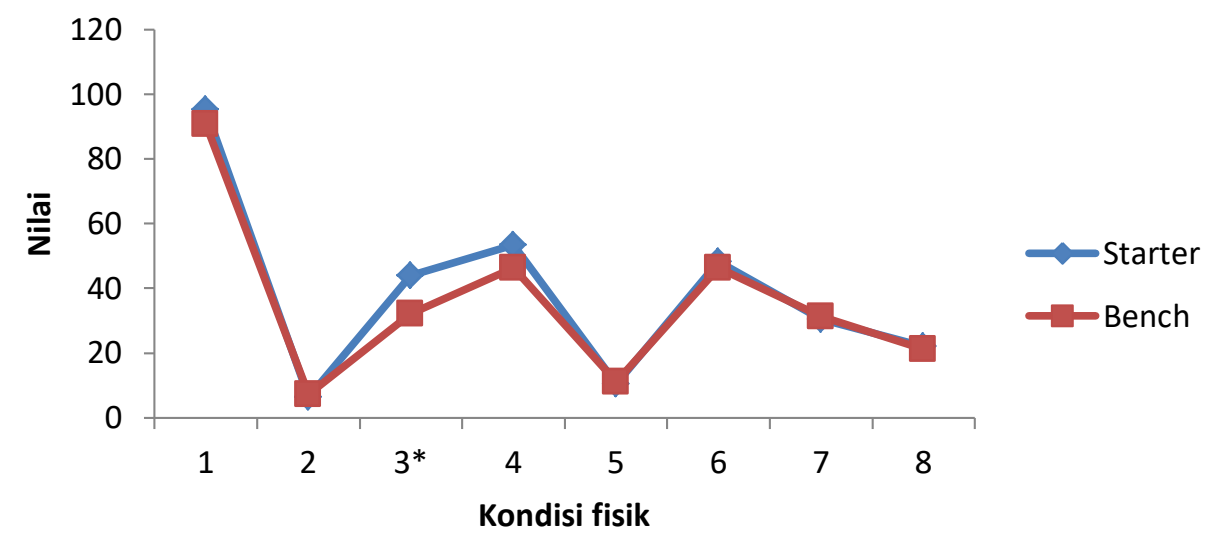

Gambar 2. Perbedaan kondisi fisik antara pemain inti dan pemain cadangan tim bola basket PPLOP Jawa tengah tahun 2019. 1=daya tahan anaerobik $(\%) ; 2=$ kecepatan (s); 3=daya tahan kekuatan dada-lengan (kali); 4=daya tahan kekuatan perut (kali); $5=$ kelincahan(s); $6=$ daya tahan aerobik $(\mathrm{ml} / \mathrm{kg} / \mathrm{min}) ; 7=$ kelentukan $(\mathrm{cm}) ; 8=\mathrm{IMT}\left([\mathrm{kg} / \mathrm{m}]^{2}\right) ;$ *significance $\mathrm{p}<0.05$

Uji beda dilakukan untuk mengetahui keberartian perbedaan pada 8 aspek kondisi fisik antara pemain inti dan pemain cadangan. Hasilnya menunjukkan adanya perbedaan yang signifikan hanya pada komponen daya tahan muskuler ekstrimitas atas yang diukur melalui tes push up. Jumlah push up yang dicapai oleh pemain inti (starter) rata-rata sebanyak 44 kali sedangkan pemain cadangan rata-rata sebanyak 32 kali (sig. <0.05). Adapun untuk komponen yang lain, perbedaan nilai yang diperoleh tidak signifikan secara statistik.

\section{Pembahasan}

Daya tahan merupakan aset yang penting bagi setiap atlet, tidak terkecuali pada cabang olahraga bola basket. Atlet yang memiliki daya tahan yang bagus akan dapat mempertahankan performanya di lapangan serta memiliki ambang batas kelelahan yang lebih tinggi. Oleh karenanya atlet tersebut akan berdaya saing yang unggul. Dalam level kompetisi bola basket yang tinggi, atlet dapat memiliki penampilan yang baik jika didukung oleh daya tahan yang prima diantaranya daya tahan kardiorespiratori maupun daya tahan muskular. Beberapa komponen fisik lain seperti daya ledak (power) maupun kecepatan serta kelincahan juga penting bagi atlet bola basket(Alemdaroğlu, 2012).

Atlet PPLOP merupakan atlet yang terbaik yang dipilih melalui jalur seleksi yang ketat sehingga wajar jika kondisi fisik atlet-atlet pilihan ini, terutama komponen daya tahan yang terpantau dalam kondisi yang prima. Akan tetapi kondisi tersebut selayaknya dapat dipertahankan dan lebih-lebih ditingkatkan jika ingin meningkatkan daya saing pemain. Terutama menyeimbangkan capaian daya tahan aerobik dan anaerobik. Gerakan dalam permainan bola basket yang didominasi gerakan dengan intensitas tinggi seperti melompat, berlari, dan merubah arah tentu membutuhkan stamina yang prima yang dapat dibentuk dari rutinitas latihan(Abdelkrim, El Fazaa, \& Jaila, 2007).

Selain daya tahan (endurance), kecepatan yang dimiliki oleh atlet bola basket PPLOP Jawa Tengah secara rata-rata juga menunjukkan hasil yang positif. Melalui tes lari 60-m rata-rata waktu

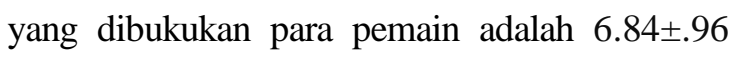
detik, angka ini dikategorikan baik sekali(American College of Sports Medicine [ACSM], 2010). Kecepatan lari yang diukur pada penelitian ini setidaknya menggambarkan 
dua dari tiga komponen kecepatan yang dikemukakan oleh Bompa (Bompa \& Carrera, 2015:83) yang mencakup respon (reaction time), kecepatan gerak, dan kecepatan lari. Hanya saja kelincahan yang diukur menunjukkan hasil yang dikategorikan sedang (10.89 \pm .67 detik). Kebutuhan akan kecepatan dari setiap cabang olahraga tentu berbedabeda. Dalam bola basket, seorang pemain lebih membutuhkan kecepatan untuk dapat melakukan perubahan arah, akselerasi dan deselerasi dengan cepat. Kecepatan yang baik jika tidak diimbangi dengan kelincahan yang bagus tentu akan mengurangi kemampuan pemain di lapangan permainan.

Bompa (2015:83) menyatakan bahwa setidaknya ada dua faktor utama yang menjadi modal bagi pengembangan kecepatan yakni genetik dan tingkat kekuatan dan daya ledak otot. Genetik memegang peran dalam menentukan sebaran otot cepat (fast-twitch) dan otot lambat (slow-twitch). Semakin banyak komposisi otot cepat maka akan semakin besar pula potensi kecepatan yang bisa dikembangkan dari seorang atlet.

Tingkat kekuatan dan daya ledak juga akan mempengaruhi tingkat kecepatan seseorang. Hal ini karena pada hakikatnya kecepatan merupakan kemampuan tubuh melakukan gerakan dengan durasi yang sesingkat-singkatnya. Melalui kapasitas otot yang didukung kekuatan dan daya ledak, akan berdampak pada semakin mudahnya mengembangkan kecepatan seseorang. Namun hal yang perlu diingat bahwa dalam cabang olahraga bola basket kecepatan yang dibutuhkan harus dibarengi dengan kelincahan karena permainan bola basket lebih banyak melibatkan lari jarak pendek yang disertai dengan gerak merubah arah. Ukuran tingkat kelincahan yang didapatkan dalam penelitian

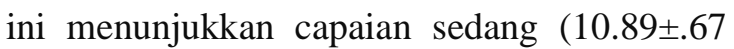
detik), artinya masih diperlukan perbaikan kondisi fisik dalam hal kelincahan agar mampu menunjang fisik atlet secara keseluruhan.
Beberapa aspek fisik lain juga memerlukan usaha peningkatan karena hasilnya yang belum cukup memuaskan. Aspek fisik yang dimaksud adalah kelentukan (flexibility) dan daya tahan muscular ekstrimitas atas (muscular endurance). Melalui test modifikasi ' $V$-sit' diperoleh hasil rata-rata $31 \pm 6.86 \mathrm{~cm}$ yang dikategorikan dalam norma sedang sedangkan tingkat daya tahan muskular yang diperoleh melalui tes push-up menunjukkan hasil yang tidak memuaskan dengan nilai rata-rata push-up 36.69 \pm 11.09 . Kelentukan merupakan kemampuan persendian tubuh untuk bergerak dalam skala jangkauan gerak (range of motion/ROM), semakin lentuk bagian tubuh, semakin besar ROM yang bisa dihasilkan dari gerakan bagian tubuh tersebut. Kelentukan yang optimal selain dapat meningkatkan kualitas gerak dapat pula mengurangi terjadinya resiko cedera saat bergerak. Shrier (2004) menyatakan bahwa peningkatan kelentukan juga dapat memberikan pengaruh positif terhadap peningkatan komponen fisik yang lain diantaranya kecepatan, kelincahan, dan tinggi lompatan.

Kelentukan dapat ditingkatkan melalui aktivitas peregangan sebelum dan sesudah latihan. Kelentukan dapat dengan mudah ditingkatkan jika aktivitas peregangan sudah dibiasakan kepada atlet sejak usia dini karena seiring bertambahnya usia secara anatomis hambatan peningkatan kelentukan tentunya akan menjadi semakin besar (Bompa \& Carrera, 2015:67). Meningkatkan kelentukan dapat ditempuh dengan menggunakan teknik peregangan PNF (propriceptive neuromuscular fasilitation) yang terbukti memiliki hasil yang lebih baik dalam meningkatkan ROM jika dibandingkan dengan peregangan statis(Yutetsu, Hisashi, Yuji, Shizuo, \& Junichiro, 2013).

Pada penelitian ini didapatkan nilai ratarata daya tahan muskuler ekstrimitas atas atlet bola basket PPLOP yang diperoleh melalui tes push up berada dalam kategori kurang 
sehingga memerlukan perhatian serius dari tim kepelatihan untuk memperbaiki capaian tersebut. Bola basket merupakan permainan yang menuntut dominasi keterampilan tangan dalam mengolah bola. Jika tangan, lengan dan bagian-bagian tubuh pendukungnya mempunyai daya tahan yang rendah maka akan mempengaruhi keterampilan pemain dalam memainkan bola basket. Peningkatan daya tahan muskuler dapat diperoleh melalui latihan kekuatan baik dengan beban internal (body weight exercise) maupun beban external (free weight exercise).

Adapun nilai IMT atlet bola basket PPLOP rata-rata dalam kategori ideal, artinya dengan skema layanan makanan yang terpadu dapat menjamin ketercukupan gizi para atlet serta mempertahankan berat dan tinggi badan dalam rasio yang ideal.

Peningkatan kapasitas fisik diterapkan melalui periodisasi latihan yang dibuat oleh pelatih. Periodisasi latihan digunakan untuk mengatur beban latihan secara sedemikian rupa agar memperoleh hasil yang optimal. Kondisi fisik yang prima mutlak diperlukan oleh semua atlet yang terlibat dalam permainan baik itu sebagai pemain inti maupun pemain cadangan. Bola basket sebagai olahraga tim membutuhkan sebaran kemampuan pemain yang merata antara pemain inti dan pemain cadangan. Hal ini dimaksudkan agar rotasi pemain dapat berjalan efektif. Akan tetapi jika kemampuan pemain tidak merata maka pelatih akan kesulitan untuk merotasi pemain karena terbatasnya opsi pemain yang memiliki kemampuan yang dibutuhkan tim. Daya tahan muskuler pada lengan dan bahu merupakan komponen yang krusial dalam permainan bola basket. Seberapa lama seorang pemain dapat mengolah bola akan menentukan keberhasilan sebuah tim. Olehkarenanya aspek ini penting untuk dimiliki setiap pemain untuk dapat bertahan dalam level persaingan yang kompetitif.

\section{SIMPULAN}

Kesimpulan pada penelitian ini yakni kondisi fisik rata-rata atlet PPLOP Bola Basket Jawa Tengah dalam kondisi yang bagus. Akan tetapi ada hasil minor yaitu komponen daya tahan kekuatan yang perlu untuk ditingkatkan agar tetap menjaga dan meningkatkan daya saing atlet.

Temuan dalam penelitian ini dapat dijadikan sebagai bahan evaluasi dalam penyusunan program latihan bagi pelatih untuk menyesuaikan kembali program latihannya dengan mengefektifkan latihan fisik agar diperoleh kondisi fisik pemain yang merata serta mampu bersaing dalam persaingan yang kompetitif dalam setiap pertandingan yang dilakukan. Item-item tes dan pengukuran dalam penelitian ini juga dapat dimanfaatkan oleh pelatih dan pemangku kepentingan yang terkait untuk memonitor tingkat kondisi fisik atlet bola basket.

Pengembangan dari penelitian ini diperlukan terutama dalam upaya untuk meningkatkan komponen fisik yang masih berada dalam kategori sedang dan kurang seperti kelentukan, kelincahan, daya tahan muskuler, dan daya tahan aerobik

\section{UCAPAN TERIMA KASIH}

Penelitian ini tidak akan terlaksana tanpa peran besar dari berbagai pihak diantaranya LPPM UMS atas skema pendanaan internal yang diberikan, Kepala balai PPLOP Jawa Tengah dan pelatih Bola Basket PPLOP Jawa Tengah atas ijin yang diberikan untuk melaksanakan penelitian serta atlet bola basket PPLOP Jawa Tengah tahun 2019 yang antusias dan kooperatif selama proses pengambilan data.

\section{DAFTAR PUSTAKA}

Abdelkrim, N. Ben, El Fazaa, S., \& Jaila, E. A. (2007). Time-motion analysis and physiological data of elite under-19-yearold basketball players during competition. 
British Journal of Sports Medicine, 41(2), 69-75.

Abian-Vicen, J., Puente, C., Gonzalez-Millan, C., Areces, F., Munoz, G., \& Del Coso, J. (2014). A caffeinated energy drink improves jump performance in adolescent basketball players. Amino Acids, 46(5), 1333-1341.

Alemdaroğlu, U. (2012). The relationship between muscle strength, anaerobic performance, agility, sprint ability and vertical jump performance in professional basketball players. Journal of Human Kinetics, 31, 149-158.

American College of Sports Medicine. (2010). ACSM's Guidelines for Exercise Testing and Prescription (8th ed.). Philadelphia: Lippincott Williams \& Wilkins.

American College of Sports Medicine. (2018). ACSM's Guidelines for Exercise Testing and Prescription (10th ed.). Lippincott Williams \& Wilkins.

Amiri-Khorasani, M., \& Kellis, E. (2015). Acute Effects of Different Agonist and Antagonist Stretching Arrangements on Static and Dynamic Range of Motion. Asian J Sports Med, 6(4), 1-6.

Arazi, H., Coetzee, B., \& Asadi, A. (2012). Comparative effect of land and aquatic based plyometric training on the jumping ability and agility of young basketball players. S Afr Res Sport Phys Edu Rec, $34,1-14$.

Bangsbo, J., Graham, T., Johansen, L., \& Saltin, B. (1994). Muscle lactate metabolism in recovery from intense exhaustive exercise: impact of light exercise. Journal of Applied Physiology, 77(4), 1890-1895.

Bompa, T. O., \& Carrera, M. (2015). Conditioning Young Athletes. Human Kinetics.

Gurses, veli V., \& Kamis, O. (2018). The
Relationship Between Reaction Time and $60 \mathrm{~m}$ Performance in Elite Athletes. Journal of Education and Training Studies, 6(12), 64-69.

Klausemann, M. J., Pyne, D. ., Foster, C., \& Drinkwater, E. . (2012). Optimising technical skills and physical loading in small-sided basketball games. Journal of Sports Sciences, 30(14), 1463-1471.

Kuroda, Y., Suzuki, N., Dei, A., Umebayashi, K., Takizawa, K., \& Mizuno, M. (2015). A Comparison of The Physical Fitness, Athletic Performance, and Competitive Achievements of Junior and Senior Tennis Players. Movement, Health \& Exercise, 4(1), 39-50.

McInnes, S. ., Carlson, J. ., Jones, C. ., \& McKenna, M. . (1995). The physiological load imposed on basketball players during competition. Journal of Sports Sciences, 13(5), 387-397.

McKeag, D. B. (2008). Handbook of Sports Medicine and Science, Basketball. (D. B. McKeag, Ed.). John Wiley \& Sons.

Morrow Jr, J. ., Mood, D., Disch, J., \& Kang, M. (2015). Measurement and Evaluation in Human Performance (5th ed.). Champaign: Human Kinetics.

Nasution, A. (2014). Tingkat Kondisi Fisik Atlet Putra Tim Bolabasket SMAN 1 Driyorejo Kabupaten Gresik Tahun 2013. Jurnal Kesehatan Olahraga, 2(2), 86-97.

Nosa, S. A., \& Faruk, M. (2013). Survei Tingkat Kebugaran Jasmani Pada Pemain Persatuan Sepakbola Indonesia Lumajang. Jurnal Prestasi Olahraga, 1(1), 1-8.

Permadi, A. G. (2017). Survey Tingkat Kondisi Fisik Atlet Bulutangkis PB. Pahlawan Sumenep. Jurnal Ilmiah Mandala Education, 3(2), 71-80.

Priambodo, A. (2013). Tingkat Kesegaran Jasmani Atlet Putra Bolabasket PPLP 
Jawa tengah Tahun 2013. Universitas Negeri semarang.

Puente, C., Abian-Vicen, J., Areces, F., Lopez, R., \& Del Coso, J. (2017). Physical and Physiological Demands of Experienced Male Basketball Players During a Competitive Game. Journal of Strength and Conditioning Research, 31(4), 956962.

Semenick, D. (1990). Tests and measurements: The T-test. Strength \& Conditioning Journal, 12(1), 36-37.

Shrier, I. (2004). Does stretching improve performance?: a systematic and critical review of the literature. Clinical Journal of Sport Medicine, 14(5), 267-273.
Yutetsu, M., Hisashi, N., Yuji, O., Shizuo, K., \& Junichiro, A. (2013). Effects of Proprioceptive Neuromuscular Facilitation Stretching and Static Stretching on Maximal Voluntary Contraction. Journal of Strength and Conditioning Research, 27(1), 192-201.

Zagatto, A., Beck, W., \& Gobatto, C. (2009). Validity of the running anaerobic sprint test for assessing anaerobic power and predicting short-distance performances. $J$ Strength Cond Res, 23(6), 1820-1827.

Zhannisa, U. H., \& Sugiyanto, F. . (2015). Model tes fisik pencarian bakat olahraga bulutangkis usia di bawah 11 tahun di DIY. Jurnal Keolahragaan, 3(1), 117126. 